Article

\title{
Chitosan/Alginate Hydrogel Dressing Loaded FGF/VE-Cadherin to Accelerate Full-Thickness Skin Regeneration and More Normal Skin Repairs
}

\author{
Lai Wei, Jianying Tan, Li Li, Huanran Wang, Sainan Liu, Junying Chen *, Yajun Weng and Tao Liu
}

check for updates

Citation: Wei, L.; Tan, J.; Li, L.; Wang, H.; Liu, S.; Chen, J.; Weng, Y.; Liu, T. Chitosan/Alginate Hydrogel Dressing Loaded FGF/VE-Cadherin to Accelerate Full-Thickness Skin

Regeneration and More Normal Skin Repairs. Int. J. Mol. Sci. 2022, 23, 1249. https://doi.org/10.3390/ ijms23031249

Academic Editor: Vijay

Kumar Thakur

Received: 9 December 2021

Accepted: 21 January 2022

Published: 23 January 2022

Publisher's Note: MDPI stays neutral with regard to jurisdictional claims in published maps and institutional affiliations.

Copyright: (C) 2022 by the authors. Licensee MDPI, Basel, Switzerland. This article is an open access article distributed under the terms and conditions of the Creative Commons Attribution (CC BY) license (https:// creativecommons.org/licenses/by/ $4.0 /$ )
Key Laboratory of Advanced Technology of Materials, Ministry of Education, Southwest Jiaotong University, Chengdu 610031, China; laiwei_myfuture@163.com (L.W.); jianying1128@126.com (J.T.); lili1993@my.swjtu.edu.cn (L.L.); huanran@my.swjtu.edu.cn (H.W.); liusainan1995@163.com (S.L.); wengyj7032@swjtu.edu.cn (Y.W.); 1t045021@gzucm.edu.cn (T.L.)

* Correspondence: chenjy@263.net; Tel.: +86-028-87634148; Fax: +86-028-87600625

\begin{abstract}
The process of full-thickness skin regeneration is complex and has many parameters involved, which makes it difficult to use a single dressing to meet the various requirements of the complete regeneration at the same time. Therefore, developing hydrogel dressings with multifunction, including tunable rheological properties and aperture, hemostatic, antibacterial and super cytocompatibility, is a desirable candidate in wound healing. In this study, a series of complex hydrogels were developed via the hydrogen bond and covalent bond between chitosan (CS) and alginate (SA). These hydrogels exhibited suitable pore size and tunable rheological properties for cell adhesion. Chitosan endowed hemostatic, antibacterial properties and great cytocompatibility and thus solved two primary problems in the early stage of the wound healing process. Moreover, the sustained cytocompatibility of the hydrogels was further investigated after adding FGF and VE-cadherin via the co-culture of L929 and EC for 12 days. The confocal 3D fluorescent images showed that the cells were spherical and tended to form multicellular spheroids, which distributed in about 40-60 $\mu \mathrm{m}$ thick hydrogels. Furthermore, the hydrogel dressings significantly accelerate defected skin turn to normal skin with proper epithelial thickness and new blood vessels and hair follicles through the histological analysis of in vivo wound healing. The findings mentioned above demonstrated that the CS/SA hydrogels with growth factors have great potential as multifunctional hydrogel dressings for full-thickness skin regeneration incorporated with hemostatic, antibacterial, sustained cytocompatibility for 3D cell culture and normal skin repairing.
\end{abstract}

Keywords: hydrogel dressing; full-thickness skin regeneration; 3D cell culture; FGF; VE-cadherin

\section{Introduction}

In the human body, the skin is the most extensive and most vulnerable tissue. Skin also plays a significant role in defending external damage and microbial infection [1]. Once the skin tissue is damaged, the cutaneous wound healing might be a complex multi-step process that involves related dermal and epidermal events. During the skin repairing process, lots of soluble factors, blood elements, extracellular matrix (ECM) and cells were involved [2]. The skin repair may generally be divided into four continuous phases: hemostasis, inflammation, proliferation and remodeling [3]. Although most incisional skin wounds can be effectively healed, excisional wounds, also called the extensive fullthickness wound usually hard to repair, causing severe infecting and thus threatening life. Thus, the design of wound dressings with multifunctional properties is highly desired.

The functions of wound dressings may include but are not limited to covering the wound and acting as a temporary barrier, guiding the reorganization of skin cells and re-integration of host wound skin tissues, including epidermis, basement membrane and dermis. An ideal skin wound dressing should meet the requirements below: sufficient 
mechanical strength, good moisture retention, appropriate surface microstructure, excellent tissue compatibility [4]. A variety of biomedical materials can be served as wound dressings, such as fibrous [5] membranes [6], polymer and polysaccharide scaffolds [7], nanoparticles [8], and hydrogels [9]. Compared with other dressing materials, hydrogels dressings $[10,11]$ are attracting increasing attention due to their adjustable physicochemical properties, similar to ECM, able to modulate the fluid balance and accelerate wound repair $[12,13]$. Several hydrogel dressings with remarkable antibacterial activity and excellent promotion to wound healing $[14,15]$. Thus, developing a multifunctional hybrid hydrogel dressing to promote the full-thickness wound healing process is highly desirable.

Chitosan (CS) [16,17] and alginates (SA) [18,19], as natural polysaccharides, have received increasing attention due to their high hydrophilicity and outstanding biocompatibility. CS [20,21], as the unique cationic polysaccharide, shows high antimicrobial activity due to the interaction between positively charged CS and the negatively charged bacterial membrane [22]. Among these materials, CS may be considered as an ideal candidate in the wound repair stages of inflammation [23]. Besides, due to the outstanding biocompatibility, suitable biodegradability and low toxicity, CS has become one of the most extensively used hydrogel dressings [24]. In addition, CS can induce local macrophage proliferation, stimulate the remodeling of ECM and thus promote early wound healing. Furthermore, CS processes abundant primary amine groups, which endows them to react with carboxyl groups [25-27]. SA, a natural anionic polysaccharide (carboxyl groups), is of particular interest for skin dressings due to their non-toxic and biocompatibility [28]. Concerning their chemical formula and structure, SA own ease of gelation kinetics and similarity to natural ECM [29], which makes them proper candidates compared to other biomaterials. Although SA lacks an adhesive motif that can initiate cell adhesion, the addition of growth factors may help improve the cell adhesion.

Growth factors belonging to the fibroblast growth factors (FGF) family play crucial roles in tissue repair and regeneration. The FGF family are small proteins and process a typical $\beta$-barrel structure as the core [30]. The FGF can be divided into three major groups: canonical, hormone-like, and intracellular. The FGF plays a vitally important role in tissue repair processes after mechanical injury, burns and chemical damage [31]. In general, the function of FGF includes stimulating cell proliferation and migration [32] FGF could also enhancing angiogenesis which promote the formation of new vessels from pre-existing vessels [33,34]. FGFs can regulate many aspects of the cell phenotype, which is critical to tissue repair. For example, for endothelial cells, FGF2 could promote lifespan extension and angiogenesis, suppress apoptosis [35]. For fibroblasts, FGF2 could suppress their differentiation to myofibroblasts. Vascular endothelial cadherin (VE-cadherin) is an endothelial-specific marker expressed by endothelial cells during vasculogenesis [36] and a major component of endothelial adherens junctions. VE-cadherin is crucial for the organization of the newborn vascular network [37]. Besides, the function of VEcadherin also includes promoting endothelial differentiation and mediating the interstitial mechanotransduction [38].

In this study, taking advantage of the hydrogen bond and covalent bond between chitosan and alginate, a series of complex hydrogels were synthesized. Furthermore, poly (ethylene glycol) diacrylate (PEGDA) was introduced to increase the mechanical property of hydrogels. These hydrogels exhibited high swelling properties, suitable degradation, proper aperture for cell growth and tunable rheological properties. Besides, the performance of hemostatic ability, antibacterial behaviors both in vitro and in vivo, cytocompatibility for L929 (epithelioid fibroblasts cells) and EC (endothelial cells) were systematically investigated. The super hemostatic, antibacterial and cytocompatibility in vitro confirmed the biocompatibility of hydrogels. Furthermore, wound closure, epidermal thickness and histological examinations were carried out to evaluate the effects of full-thickness wound healing. In a word, all the results demonstrated that these complex hydrogels possess fantastic ability for the full-thickness skin defected repairing process, which is involved in antibacterial, proper hemostatic, cell proliferation and tissue regeneration. 


\section{Results}

\subsection{Physical Characterization of Complex Hydrogels}

The structural formula and schematic drawing of the CS/SA/PEGDA complex hydrogels are showed in Figure 1. The volume ratio of mixing solution and SA were 6:4, 7:3, 8:2, and were named C6-S4, C7-S3, C8-S2, respectively. After that, VE-cadherin $(20 \mu \mathrm{g} / \mathrm{mL})$ and FGF (100 ng/mL) were added to the C8-S2 hydrogel and signed as C8-S2-V and C8-S2-F, respectively. The hydrogel added to the VE-cadherin $(20 \mu \mathrm{g} / \mathrm{mL})$ and FGF $(100 \mathrm{ng} / \mathrm{mL})$ at the same time were signed as C8-S2-F-V.

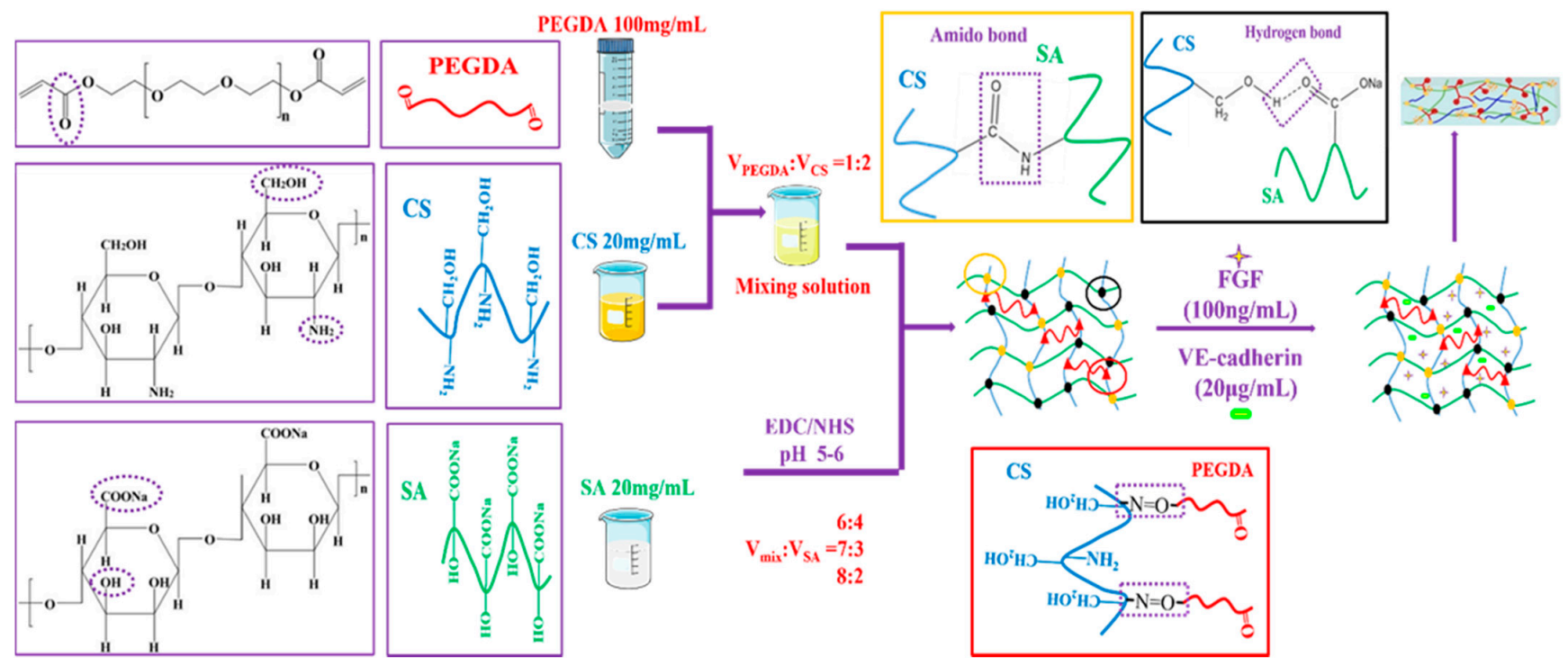

Figure 1. The structural formula of PEGDA, CS, SA and the schematic drawing of complex hydrogels.

The complex hydrogels were semi-transparent and non-flowing condition. The proper water uptake ability of hydrogel helps to accelerate the process of wound healing through absorbing exudate from wounds and reducing the risk of infection, which was one of the requirements for wound dressings. Swelling tests were used to determine the swelling ratio (SR) of the complex hydrogels, which were analyzed by the weight ratio of dried state (Wd) and fully swollen state (Ws). The equilibrium mass swelling of complex hydrogel was calculated according to the formula: $\mathrm{SR}=(\mathrm{Ws}-\mathrm{Wd}) / \mathrm{Wd}$. As showed in Figure $2 \mathrm{a}$, the swelling ratio of C6-S4, C7-S3 and C8-S2 hydrogels were 4.87, 5.32 and 8.86, respectively. The equilibrium mass swelling of hydrogel increases with the increase of the amount of chitosan in the hydrogel.

Figure $2 b$ results showed scanning electron microscope (SEM) micrographs of the cross section of the complex hydrogels. The pores present elliptical shapes, and the pore size changed with the different proportions of hydrogels. In general, with the increase of chitosan content, the major axis of elliptical shapes increased. According to the calculation, C6-S4 showed the smallest pore size (about $32 \mu \mathrm{m}$ for minor axis and $64 \mu \mathrm{m}$ for major axis), and C8-S2 showed the largest pore size (about $38 \mu \mathrm{m}$ for minor axis and $105 \mu \mathrm{m}$ for major axis). Pore size at dozens of micrometers is beneficial to the transportation of nutrients and convenient for the ingrowth of cells. The different aperture sizes were mainly due to the different crosslinking degrees of the hydrogel, which suggested the crosslinking degree decreased with the increase of chitosan content.

To analyze the influence of different chitosan content on the rheological properties of the complex hydrogels, the curves of storage modulus $\left(G^{\prime}\right)$ and loss modulus $\left(G^{\prime \prime}\right)$ of the hydrogels over frequency were recorded. The $\mathrm{G}^{\prime}$ of C6-S4 hydrogel (5848 Pa) was higher than C7-S3 (4428 Pa) hydrogel and C8-S2 (2778 Pa) hydrogel at $100 \mathrm{~Hz}$. The rheological properties showed the same rule at low frequency. The $\mathrm{G}^{\prime}$ of $\mathrm{C} 6-\mathrm{S} 4$ hydrogel (764 Pa) was higher than C7-S3 (302 Pa) hydrogel and C8-S2 (211 Pa) hydrogel at $10 \mathrm{~Hz}$. This is because 
more chitosan content in the hydrogel decreased the crosslinking density and thus leading to the lower $\mathrm{G}^{\prime}$ of the hydrogel (Figure 2c).

(a)

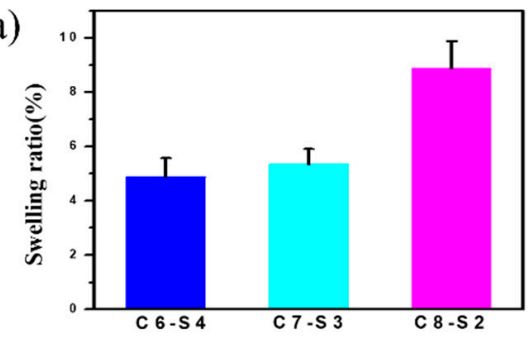

(c)
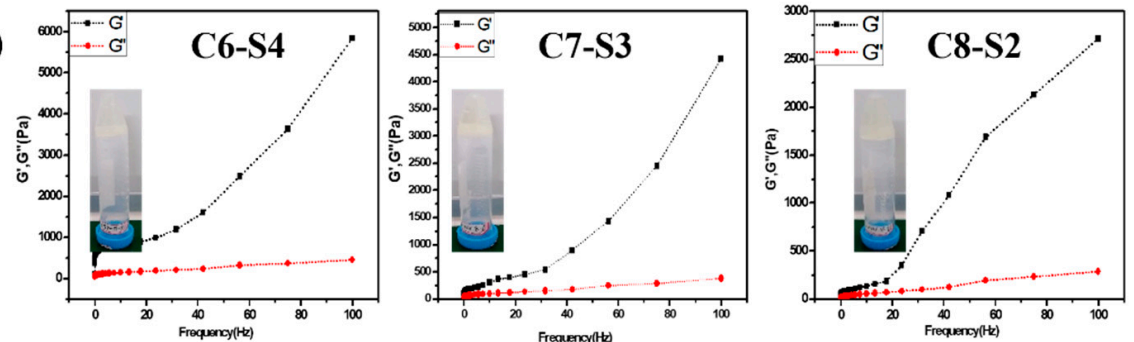

(d)

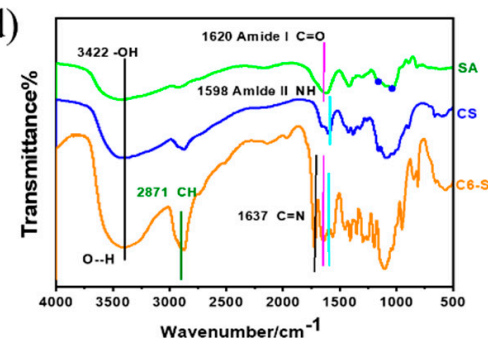

(b)
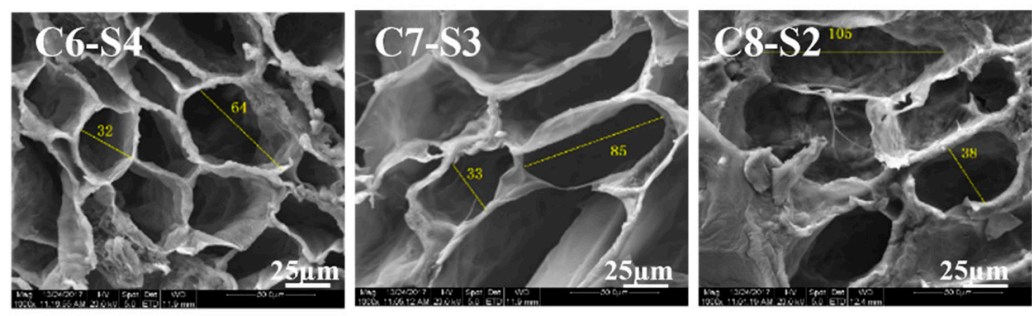

(e)

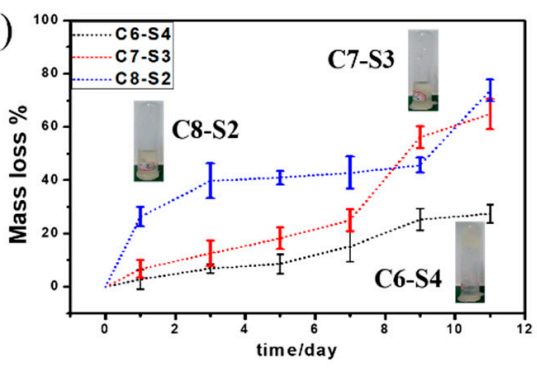

(f)
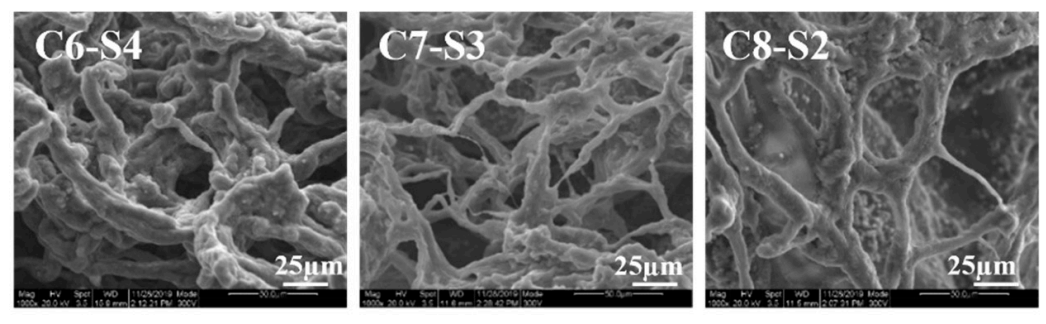

Figure 2. Physical characterization of complex hydrogels. (a) The swelling ratio of complex hydrogels (mean $\pm \mathrm{SD}, n \geq 3$ ). (b) SEM micrograph of complex hydrogels. The scale bar stands for $25 \mu \mathrm{m}$ in (b) (c) Rheological behavior of complex hydrogels, in which the forming state of com- plex hydrogels were showed in the left of each picture. (d) The FTIR of alginate (SA), chi-tosan (CS) and C6-S4 hydrogel. (e) The mass loss of complex hydrogels within 11 days of degra-dation. (f) SEM micrograph of complex hydrogels after 11 days of degradation. The scale bar stands for $25 \mu \mathrm{m}$ in (f).

The fourier transform infrared spectroscopy (FTIR) of alginate (SA), chitosan (CS) and C6-S4 hydrogel were showed in Figure 2d. The characteristic peak of hydrogen bond may be found at $3422 \mathrm{~cm}^{-1}$, The characteristic peak of amido bond and carbon and oxygen double bond may be found at $1598 \mathrm{~cm}^{-1}$ and $1620 \mathrm{~cm}^{-1}$, respectively. The characteristic peak of carbon and nitrogen double bond may be found at $1637 \mathrm{~cm}^{-1}$.

After immersing in PBS for 11 days, the hydrogels condition was taken photos (Figure 2e). For the C6-S4 sample, the hydrogel was almost complete and maintained a non-flowing state. In contrast, for C7-S3 and C8-S2 samples, the hydrogel resolved in PBS with large pieces of gels and represented a flowing state. Degradation tests were used to determine the Degradation ratio (DR) of the complex hydrogels. Firstly, the complex hydrogels were immersed in $0.01 \mathrm{M} \mathrm{PBS}$ at $37^{\circ} \mathrm{C}$ with shaking at $70 \mathrm{rpm}$ until the weight of all hydrogels was kept constant and the weight were denoted as $\mathrm{W}_{0}$. At the predetermined time, the hydrogels were taken out, rinsed using RO water to remove excess salinity, the superficial water of gels were removed by filter paper, and the weight was denoted as $\mathrm{W}^{\prime}$. DR of hydrogels was analyzed by the formula: $\mathrm{DR}=\left(\mathrm{W}_{0}-\mathrm{W}^{\prime}\right) / \mathrm{W}_{0} \times 100 \%$. According to the calculation, for C6-S4, C7-S3 and C8-S2 hydrogel, the mass loss was $15.18 \%, 24.99 \%$ and $42.81 \%$ after degradation for 5 days, respectively. Similarly, for C6-S4, C7-S3 and C8-S2 hydrogel, the mass loss was $27.40 \%, 64.88 \%$ and $73.73 \%$ after degradation for 11 days, respectively (Figure 2e). 
Figure $2 \mathrm{f}$ showed SEM micrographs of the cross section of the complex hydrogels after degradation for 11 days. Compared to the SEM micrographs before and after degradation, the pore size became larger, and communicating pores appeared. In general, after degradation for11 days, these hydrogels still maintained hydrogel condition and processed certain crosslinking degrees. According to the SEM, with the increase of chitosan content, the pore size of the hydrogel increased and the connection between holes thinner.

\subsection{Hemolysis and Whole Blood Dynamic Coagulation Evaluation Results}

As showed in Figure 3a, the supernatant is transparent and without apparent hemolysis. Furthermore, the hemolysis ratio of all the hydrogels were less than $5 \%$ (Figure $3 b$ ), which accorded with the standard of blood contacted material. When the blood is connected to the hydrogels, the connection may lead to the rupture of red blood cells and cause hemolysis. Therefore, the hemolysis test is an essential experiment for the safety of blood connected materials.

(a)

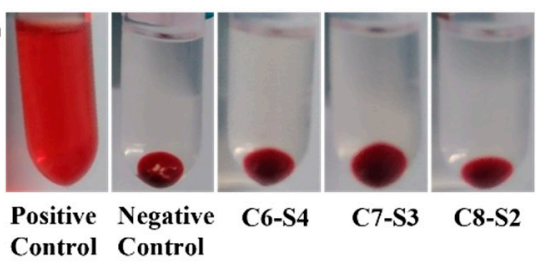

(b)

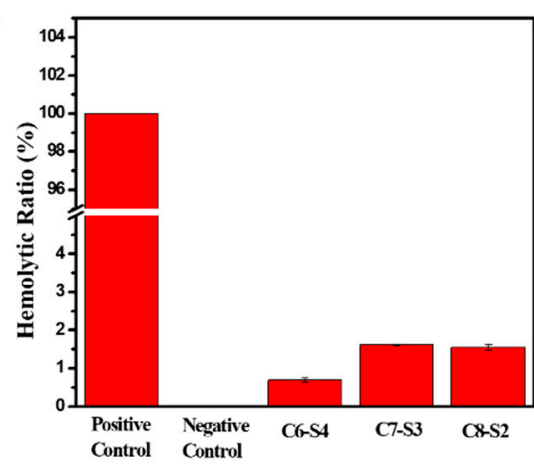

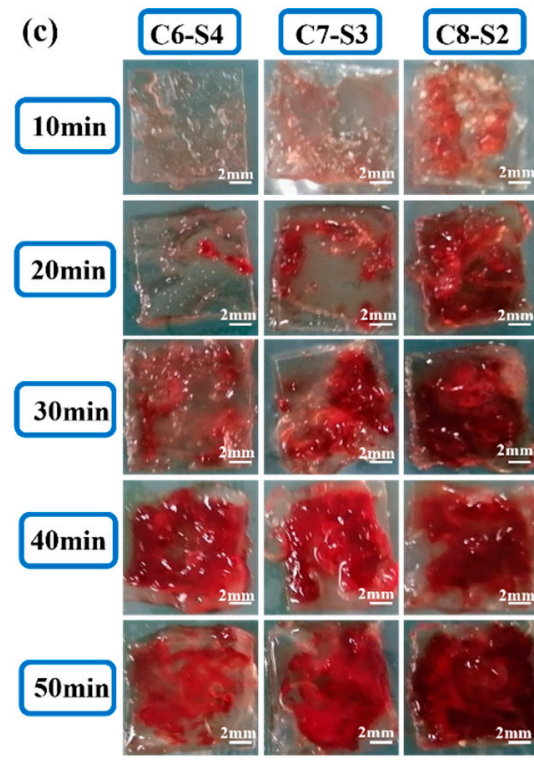

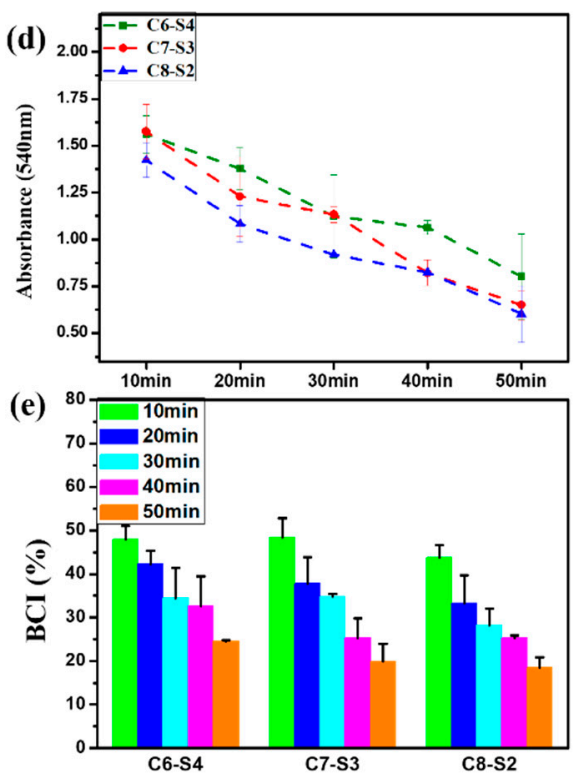

Figure 3. Blood compatibility evaluation of complex hydrogels. (a) The photos of complex hydrogels). (b) The hemolytic ratio of complex hydrogels. (mean $\pm \mathrm{SD}, n \geq 3$ ). (c) The photos of whole blood assay of complex hydrogels at different times. The scale bar stands for $2 \mathrm{~mm}$ in (c). (d) The whole blood assay absorbance of complex hydrogels at different times. (mean $\pm \mathrm{SD}, n \geq 3$ ). (e) The BCI of complex hydrogels at different times (mean $\pm \mathrm{SD}, n \geq 3$ ).

The whole blood dynamic coagulation assay was carried out to detect the coagulation after the blood was connected to the hydrogels. After the hydrogel was connected to the blood for 10, 20, 30, 40 and $50 \mathrm{~min}$, the blood clots that coagulated on hydrogels were showed in Figure 3c. For C6-S4 hydrogels, there were hardly any blood clots within $20 \mathrm{~min}$, only a tiny amount of blood clots was formed during 20-30 min, and mass of blood clots began to form after $30 \mathrm{~min}$. These results implied that the formation of large blood clots was postponed to $30 \mathrm{~min}$ after the hydrogel connected to the blood for C6-S4. In contrast, for C8-S2 hydrogel, there were few blood clots after the hydrogel connected to the blood for $10 \mathrm{~min}$. After that, more and more blood clots began to form, which means the significant coagulation reaction occurred after $10 \mathrm{~min}$ connection. Figure $3 \mathrm{~d}$ showed the absorbance of hydrogels at different point times. As time went by, more and more blood involved in the coagulation reaction; the uncoagulated blood became less and led to a lower absorbance. Therefore, the lower the absorbance, the better the coagulation effect. The blood coagulant index (BCI) of hydrogels were analyzed by the following formula: As $/ \mathrm{Aw} \times 100 \%$. After the connection of $10 \mathrm{~min}$, the BCI of all hydrogels were above $40 \%$, which exhibited soft 
coagulation and prevented the blockage of capillaries (Figure 3e). Ten minutes later, the C8-S2 hydrogels began to form blood clots to prevent the hemorrhage of large vessels.

\subsection{Antibacterial Activity Assessment}

The antibacterial activities of complex hydrogels against Gram-negative bacteria E. coli and Gram-positive bacteria $S$. aureus were conducted by surface antibacterial assay, and LB agar gel plates without hydrogels were set as control and marked as blank. After incubation at $37^{\circ} \mathrm{C}$ for $12 \mathrm{~h}$, the hydrogel plates and agar gel plates were taken photos to observe the colony-forming units (CFUs) on each plate. There were no CFUs on every plate (Figure $4 \mathrm{a}, \mathrm{d}$ ). Then, in order to detect the bacteria on each plate, $1 \mathrm{~mL}$ sterilized PBS was added to each hydrogel plate to dissolve survived bacteria and then the suspension was spaced on the agar gel surfaces and incubated. The killing efficiency was calculated using the following formula: $\left(\mathrm{N}_{1}-\mathrm{N}_{2}\right) / \mathrm{N}_{1} \times 100 \%$, where $\mathrm{N}_{1}$ refers to the number of CFUs of control, and $\mathrm{N}_{2}$ refers to the number of CFUs of the survive to count on complex hydrogels. At the bacterial concentrations of $10^{3}$ and $10^{5} \mathrm{CFU} / \mathrm{mL}$, the CFUs were not found on the complex hydrogels, and a large amount of CFUs appeared on the control plate (agar gel), exhibiting $100 \%$ killing efficiency against $E$. coli. At the bacterial concentrations of $10^{2}$ and $10^{4} \mathrm{CFU} / \mathrm{mL}$, the CFUs were not found on the complex hydrogels, and a large amount of CFUs appeared on the agar gels, exhibiting $100 \%$ killing efficiency against $S$. aureus. When the bacterial concentration was increased to $10^{6} \mathrm{CFU} / \mathrm{mL}$, the hydrogels also exhibited high killing efficiency against both microorganisms. The killing efficiency of C6-S4, C7-S3 and, C8-S2 hydrogel against E. coli was up to $97.1 \%, 100 \%$ and $100 \%$, respectively (Figure $4 \mathrm{~b}$ ). Similarly, the killing efficiency of C6-S4, C7-S3 and, C8-S2 hydrogel against S. aureus were up to $96.5 \%, 100 \%$ and $100 \%$, respectively (Figure $4 \mathrm{e}$ ). The process of wound healing may be delayed or cause infection due to bacterial infection. Therefore, the antibacterial assessment aiming to detect the antibacterial ability of hydrogel as wound dressings are of vital importance. So, as an ideal wound dressing, the antibacterial ability should become their inherent property which could reduce the complications and accelerate the healing process of the wound site.
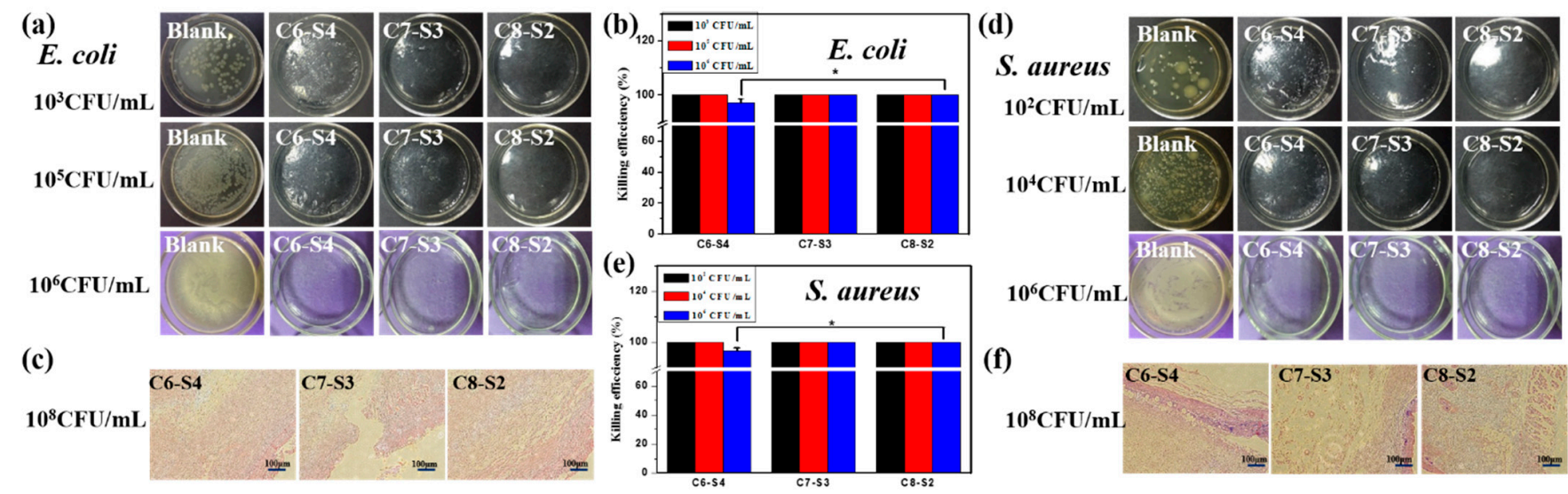

Figure 4. Antibacterial activity evaluation of complex hydrogels. (a) Bacteriostatic pictures of complex hydrogels for E. coli under the $10^{3} \mathrm{CFU} / \mathrm{mL}, 10^{5} \mathrm{CFU} / \mathrm{mL}$ and $10^{6} \mathrm{CFU} / \mathrm{mL}$ bacterial. (b) The killing efficiency of hydrogels against $E$. coli. (mean $\pm \mathrm{SD}, n \geq 3,{ }^{*} p<0.05$ ). (c) Gram stain pictures of complex hydrogels after animals affected with $10^{8} \mathrm{CFU} / \mathrm{mL}$ E. coli for $24 \mathrm{~h}$. The scale bar stands for $100 \mu \mathrm{m}$ in (c). (d) Bacteriostatic pictures of complex hydrogels for S. aureus under the $102 \mathrm{CFU} / \mathrm{mL}$, $104 \mathrm{CFU} / \mathrm{mL}$ and $106 \mathrm{CFU} / \mathrm{mL}$ bacterial concentration. (e) The killing efficiency of hydrogels against S. aureus. (mean $\pm \mathrm{SD}, n \geq 3,{ }^{*} p<0.05$ ). (f) Gram stain pictures of complex hydrogels after animals affected with $108 \mathrm{CFU} / \mathrm{mL}$. aureus for $24 \mathrm{~h}$. The scale bar stands for $100 \mu \mathrm{m}$ in (f).

The in vivo antibacterial activities of complex hydrogels against E. coli and S. aureus were evaluated via rats' full-thickness infected skin defect model. After adding the bacterial 
suspension to the defected skin for $30 \mathrm{~min}$, hydrogel dressing was covered to the defected skin for $24 \mathrm{~h}$, and the wound tissues were harvested and stained by the gram. The tissue containing E. coli could appear red pattern, the tissue containing S.aureus could appear bluish violet pattern, and the healthy tissue could appear pink pattern. The more red or bluish violet patterns, the more E. coli or S. aureus bacteria. For E. coli groups, no red pattern appeared on all the hydrogel groups, suggesting the excellent antibacterial property against E. coli (Figure 4c). For S. aureus groups, there were little bluish violet patterns on the C6-S4 hydrogel group, and there were scarcely any bluish violet patterns on the C8-S2 hydrogel group (Figure 4f). Therefore, C8-S2 hydrogel showed better antibacterial properties than the C6-S4 hydrogel group against $S$. aureus.

\subsection{Three-Dimensional Encapsulation of Cells in Complex Hydrogels}

To further evaluate the cytocompatibility of hydrogels, the L929 cells and ECs were encapsulated into the hydrogels. The morphology of adherent cells was stained by rhodamine 123, and the number of cells was detected by CCK-8 assay. As showed in Figure 5a, the morphology of endothelial cells on a tissue culture plate (TCP) showed a typical cobblestone shape morphology. However, the morphology of endothelial cells on hydrogels (C6-S4, C7-S3 and C8-S2) showed a spheroidal morphology and un-spread state (Figure 5a). In terms of cell viability, all the hydrogel groups showed no apparent difference within five days (Figure 5b). However, in terms of the proliferation of cells, the C8-S2 hydrogel revealed better proliferation than the C6-S4 hydrogel (Figure 5c). The morphology of L929 in hydrogels was also analogous with the EC, which exhibited spherical and non-spread shape (Figure 5d). For the culture of L929, the C8-S2 hydrogel exhibited a significant difference with the C6-S4 hydrogel in the aspects of cell viability and proliferation (Figure 5e,f), indicating the promoting effect of chitosan on cell proliferation.
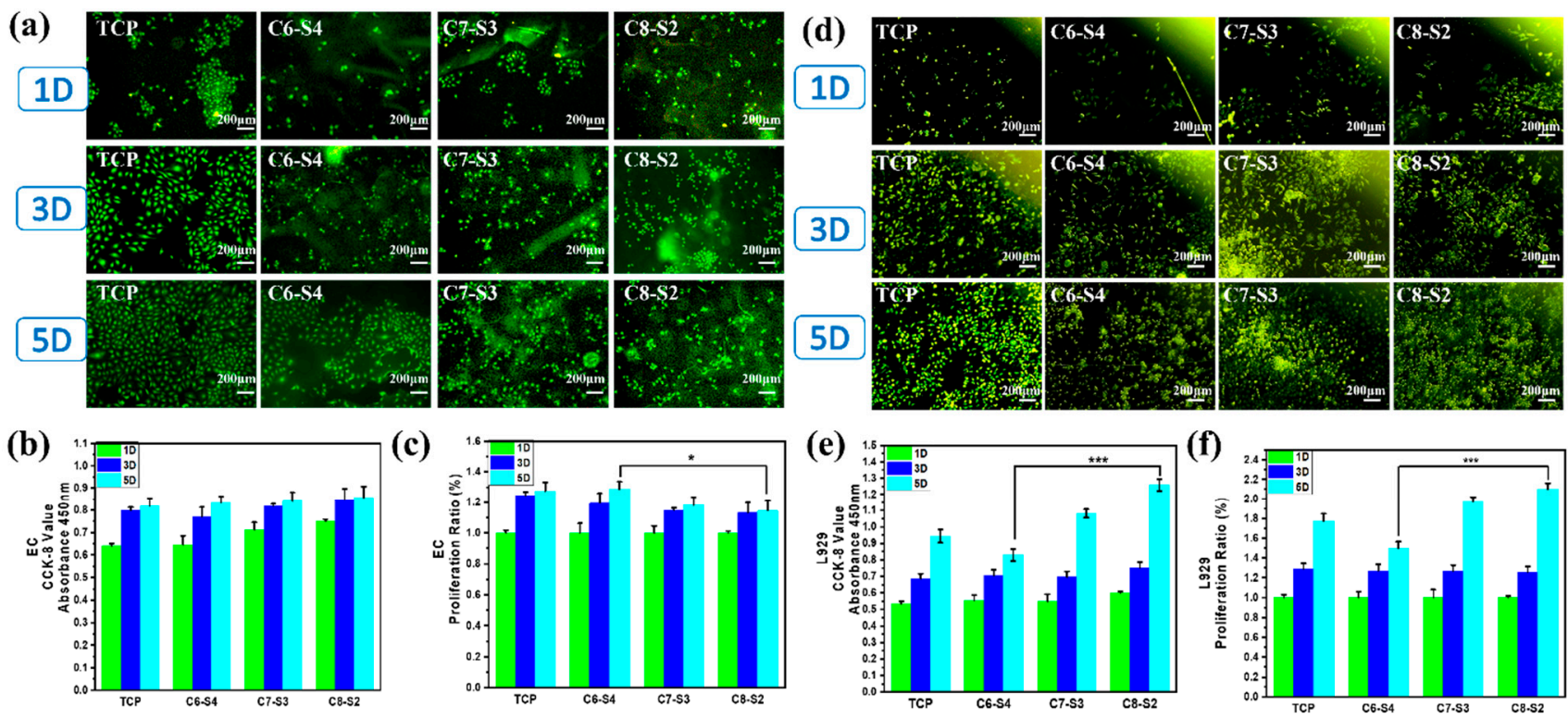

Figure 5. Evaluation of cells compatibility. (a) EC morphology of complex hydrogels. The scale bar stands for $200 \mu \mathrm{m}$ in (a). (b) The CCK-8 results of EC. (mean \pm SD, $n \geq 3,{ }^{*} p<0.05$ ). (c) The proliferation ratio of EC. (mean $\pm \mathrm{SD}, n \geq 3,{ }^{*} p<0.05$ ). (d) L929 morphology of complex hydrogels. The scale bar stands for $200 \mu \mathrm{m}$ in (d). (e) The CCK-8 results of L929. (mean $\pm \mathrm{SD}, n \geq 3^{* * *} p<0.01$ ).

(f) The proliferation ratio of 1929 . (mean $\pm \mathrm{SD}, n \geq 3$, *** $p<0.01$ ).

\subsection{Three-Dimensional Encapsulation of Two Factors and Two Cells in Complex Hydrogels}

To further evaluate the cytocompatibility of these hydrogels, the co-culture of L929 and EC with the incorporation of FGF and VE-cadherin were carried out. As showed in Figure 6a, there were only a few cells on all the hydrogel samples within three days. The 
cell viability of all hydrogel groups on the 1st and 3rd days showed no noticeable difference (Figure 6b). However, the number of cells on the 7th day significantly increased compared to the 3rd day, demonstrating that the cells grew well and were in a state of proliferation. After 12 days' co-incubation, C8-S2-F and C8-S2-F-V hydrogels exhibited higher cell number and better cell proliferation than other hydrogels, indicated the promoting effect of FGF on cells proliferation (Figure 6c). The above experiments confirmed the brilliant cytocompatibility on the co-culture of L929 and EC. Generally speaking, cells tend to form multicellular spheroids (Figure 6d). At the same time, the transportation of oxygen and nutrients to the core may be difficult when the spheroids grow. Therefore, the spheroids' diameter is limited to 200-400 $\mu \mathrm{m}$ [39].

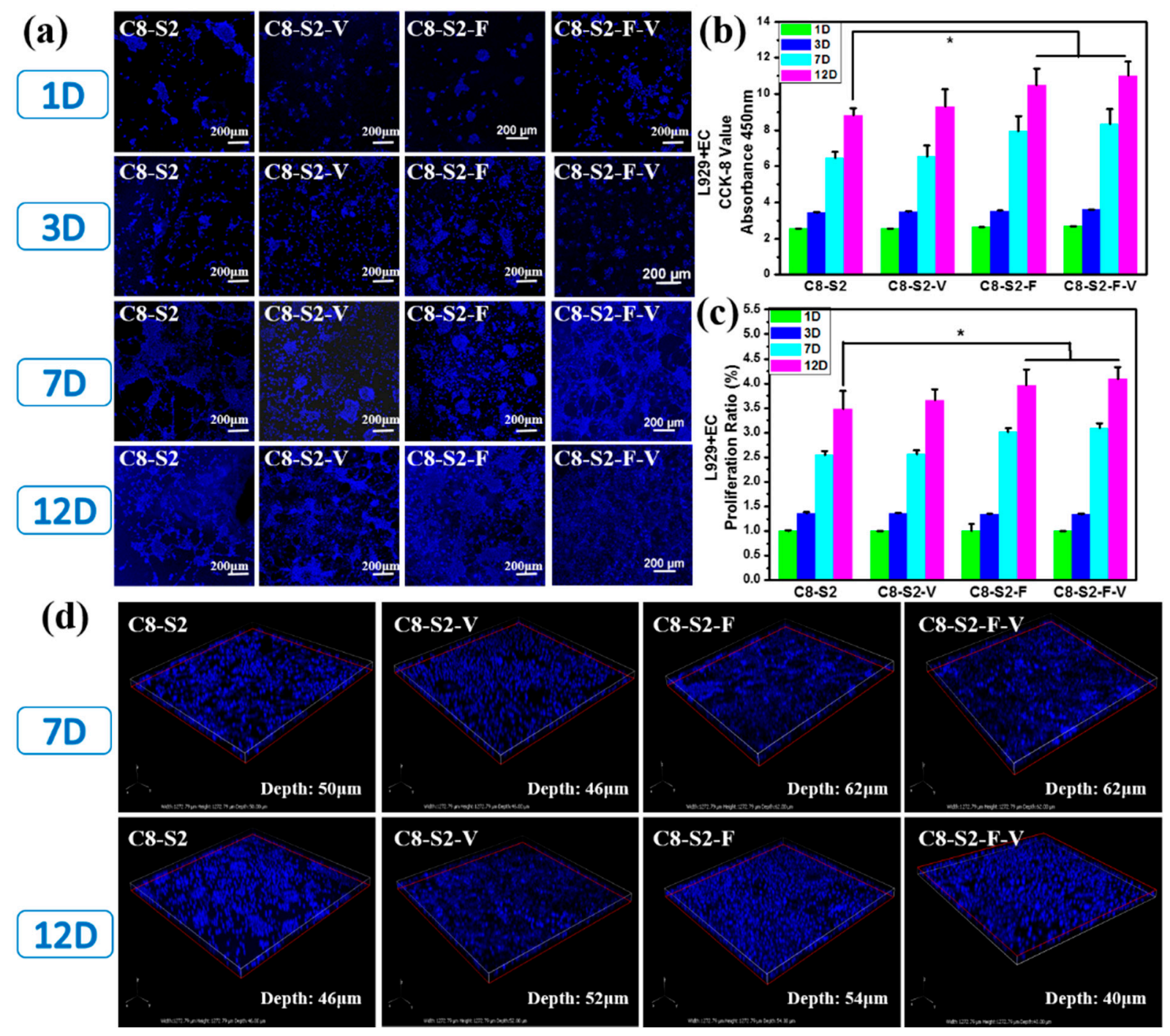

Figure 6. Evaluation of L929\&EC co-culture compatibility. (a) Morphology of L929\&EC of complex hydrogels. The scale bar stands for $200 \mu \mathrm{m}$ in (a). (b) the CCK-8 results of L929\&EC; (c) the proliferation ratio of L929\&EC. (mean $\pm \mathrm{SD}, n \geq 3,{ }^{*} p<0.05$ ); (d) the 3D morphology of L929\&EC and the complex hydrogels.

\subsection{In Vivo Repair and Regeneration Evaluation}

To further evaluate the healing process of wound skin, a full-thickness infected skindefect rat model (Figure 7a) were prepared, and histological analysis was performed. As time went by, the wound areas gradually became smaller (Figure 7b). Specifically, for groups hydrogel with factors (C8-S2-V, C8-S2-F and C8-S2-F-V), the wound areas were smaller than the primary hydrogel group (C8-S2) at 3, 7 and 14 days after surgery. 
Therefore, the percentage of wound closure of hydrogel with factors was higher than the pure hydrogel group. Additionally, compared to the $\mathrm{NaCl}$ group, the groups of hydrogels with factors showed complete and more appropriate epithelial thickness on the 14th day (Figure 7c). The epidermal thickness of hydrogel with factors was closer to normal healthy tissue $(70-120 \mu \mathrm{m})$. For further insight into wound regeneration, hematoxylin eosin (H\&E) staining was performed to analyze the changes of epidermal, dermis, skin appendages and new blood vessels. By monitoring the wound site in the whole stages of wound healing (3-14 d), the inflammatory response reduced and no obvious inflammatory response for all the groups on the 7th day after surgery (Figure 7d). New blood vessels are crucial to wound healing by providing nutrients to the damaged sites. In general, new blood vessels and skin appendages like hair follicles were observed in all the groups. On day 14, the group for hydrogel with factors showed better-organized granulation tissue at wound microenvironment. As showed in Figure 7d, hydrogel groups exhibited more blood vessels and hair follicles than the $\mathrm{NaCl}$ group on the 14th day. These results indicated that the hydrogel groups, especially for C8-S2-F and C8-S2-F-V groups, were beneficial to extracellular matrix remodeling and tissue regeneration. Hydrogels with stereoscopic structure provide cells with three-dimensional growth, promote the interaction between biomolecules, cells and tissues and thus enhance the wound healing process. In addition, the micro-pores in the hydrogels make it easy for cells and nutrients to transportation and communication.

(a)

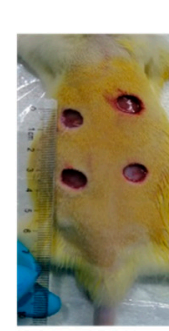

(b)

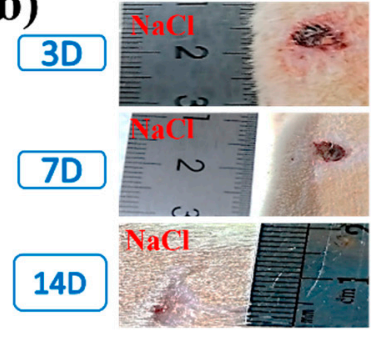

(d) (c)

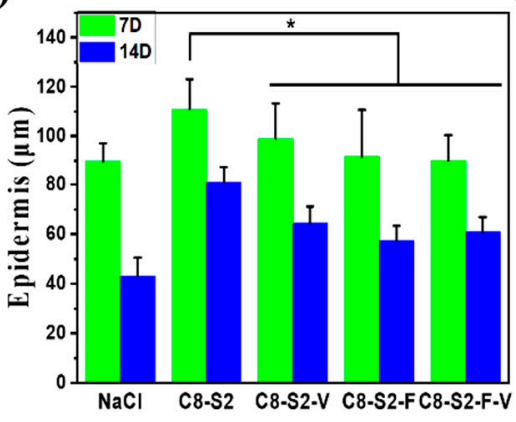

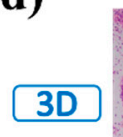
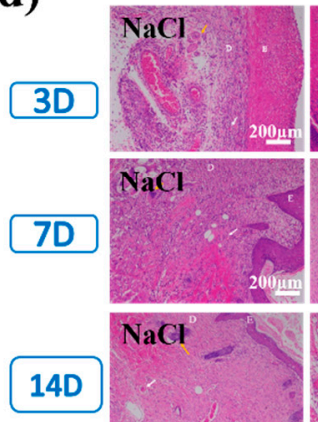
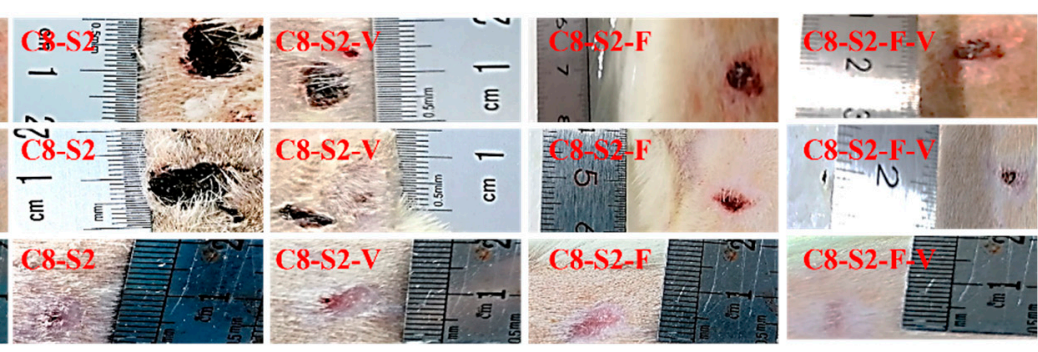

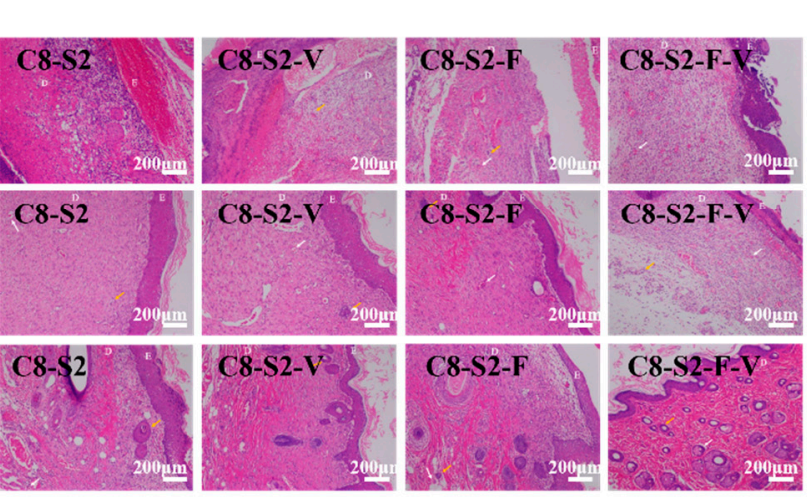

Figure 7. In vivo repair and regeneration evaluation of complex hydrogels. (a) Skin repair trauma experiments of complex hydrogels; (b) The appearance of skin wound for 3, 7, 14 days observation of repair experiments; (c) Epidermis thickness for different groups on 7 th and 14th days. (mean $\pm S D$, $n \geq 3,{ }^{*} p<0.05$ ) (d) H\&E staining of tissue sections of skin wound for 3, 7, 14 days (blood vessels: white arrows; hair follicles: orange arrows; E were epidermal layer and D were dermal layer). The scale bar stands for $200 \mu \mathrm{m}$ in (d).

\section{Discussion}

\subsection{The Influence of Chitosan on the Biological Properties of the Complex Hydrogels}

The formation of complex hydrogels was showed in Figure 1. There were mainly three types of chemical bonds in the hydrogels: (1) Hydrogen bond between the hydroxy of chitosan and the carboxyl of alginate, which is the main bonding in the hydrogel. This bonding can support the formation of hydrogel independently without the adding of EDC/NHS. 
1-3-Dimethylaminopropyl-3-ethylarbidiimide hydrochloride (EDC, $\mathrm{C} 8 \mathrm{H} 17 \mathrm{~N} 3 \cdot \mathrm{HCl})$ and $\mathrm{N}$-hydroxysuccinimide (NHS) are often used as binding agents of the amino and carboxyl groups. (2) The amido bond between the amino of chitosan and the carboxyl of alginate, whose formation had to rely on the adding of EDC/NHS. (3) Carbon and nitrogen double bond between carbon and oxygen double bond of PEGDA and the amino of chitosan, which could increase the stability of the hydrogel. Additionally, the increased concentration of PEGDA could enhance the rheological properties of the hydrogels. Moreover, with the introduction of $\mathrm{NaHCO}_{3}$, the pore size of the hydrogel is adjustable through the concentration of $\mathrm{NaHCO}_{3}$. In general, through the controlled ratio and concentration of these three materials, the hydrogels could be adjustable in terms of the pore size, degradation rate and rheological properties and thus further influence the biological properties of the hydrogels.

Concerning the coagulation affect and better cytocompatibility, C8-S2 hydrogels were better than C6-S4 hydrogels. All the hydrogels own the same excellent antibacterial effect. Therefore, the increase of chitosan could promote the coagulation, antibacterial and adhesion of cells. Firstly, the hemostatic effects of chitosan took place mainly via the following three mechanisms: (1) Stimulation of platelets. There were lots of literatures have showed that chitosan could induce platelet adhesion and aggregation [40]. (2) Aggregation of red blood cells. Recently, more evidence showed that the hemostatic promotion of chitosan was independent of traditional clotting pathways [41,42]. Due to the opposite charges of chitosan and red blood cells, chitosan attracted red blood cells and formed a "mucoadhesive barrier" via direct interaction at the wound site to stop the bleeding [43]. (3) Alteration of the structure of fibrinogen. The electrostatic forces of ionized chitosan may result in changes in the structure and function of fibrinogen. Secondly, the antibacterial mechanism of chitosan may be explained by the two following [44]: (1) Permeabilization. Chitosan could cause the permeabilization of bacterial via the electrostatic interaction between chitosan and bacteria. The permeabilization may cause the leakage of intracellular substances and thus lead to the death of bacterial. (2) Binding with the nucleic acid. Some research showed that chitosan could affect the DNA expression via binding with the nucleic acid of bacteria. Besides, many factors could affect the antibacterial of chitosan, such as the deacetylation degree and concentration of chitosan, $\mathrm{pH}$ value, temperature and chitosan derivatives, etc.

\subsection{The Influence of FGF and VE-Cadherin in 3D Hydrogels on the Cell Proliferation and Tissue Regeneration}

Cells used to be cultured in two-dimensional plates, which have been proved to distort the behaviors and functions of cells compared to the cells in vivo. In 2D cells culture plates, cells usually cannot establish sufficiently efficient cell to cell links and cell to extracellular matrix (ECM) links, which may induce the changes of cells' morphology and gene expression. Therefore, to obtain the same morphology and functions as cells in vivo, the design of a three-dimensional cell culture niche was introduced to mimic the microenvironment in vivo, which could provide sufficient cell to cell links and interactions [10]. However, the difficulties of 3D cell culture are the supplement of oxygen and nutrient for the inner cells, which has become a bottleneck of the hydrogel application. An ideal 3D cell culture niche ought to possess excellent biocompatibility for cells proliferation and appropriate porous structure for the transportation of oxygen and nutrient. According to the results mentioned above, the C8-S2 hydrogels could be designed as a great 3D cell culture niche. With the adding of FGF and VE-cadherin, this 3D cell culture niche became more excellent. Generally, FGF and VE-cadherin both could induce the adhesion, proliferation and migration of cells through the following signaling pathways showed in Figure 8.

The combination of FGF and FGFR may result in phosphorylation of FGF and activate the following signaling pathways [25]: the binding of FGFR to the adaptor protein (CRKL) may result in the bonding of FRS2 $\alpha$, and thus leads to the adaptor protein (GRB2 and GAB1). GRB2 could activate the Ras-MAPK signaling pathway. At the same time, GAB1 could activate the PI3K-AKT signaling pathway. The interactors of VE-cadherin and 
stabilized endothelial adherens junctions were showed in Figure 8. The interaction of $\alpha$-catenin with VE-cadherin needs to via $\beta$-catenin, which is dynamically contacted to the cytoskeleton, thus activating F-actin and PI3K/AKT pathway. In stabilized endothelial adherens junctions, the activity of the PI3K/AKT pathway are induced in two ways; one is the phosphorylation of 120, 14-3-3 complex and YAP, the other is CCM1, CCM2 and CCM3 [45]. VE-cadherin can also form complex with many different transmembrane signaling systems, such as the vascular endothelial growth factor receptor-2 and the FGFR1, etc. These complexes are essential in terms of the regulation of the activities of the cell-tocell junctions.

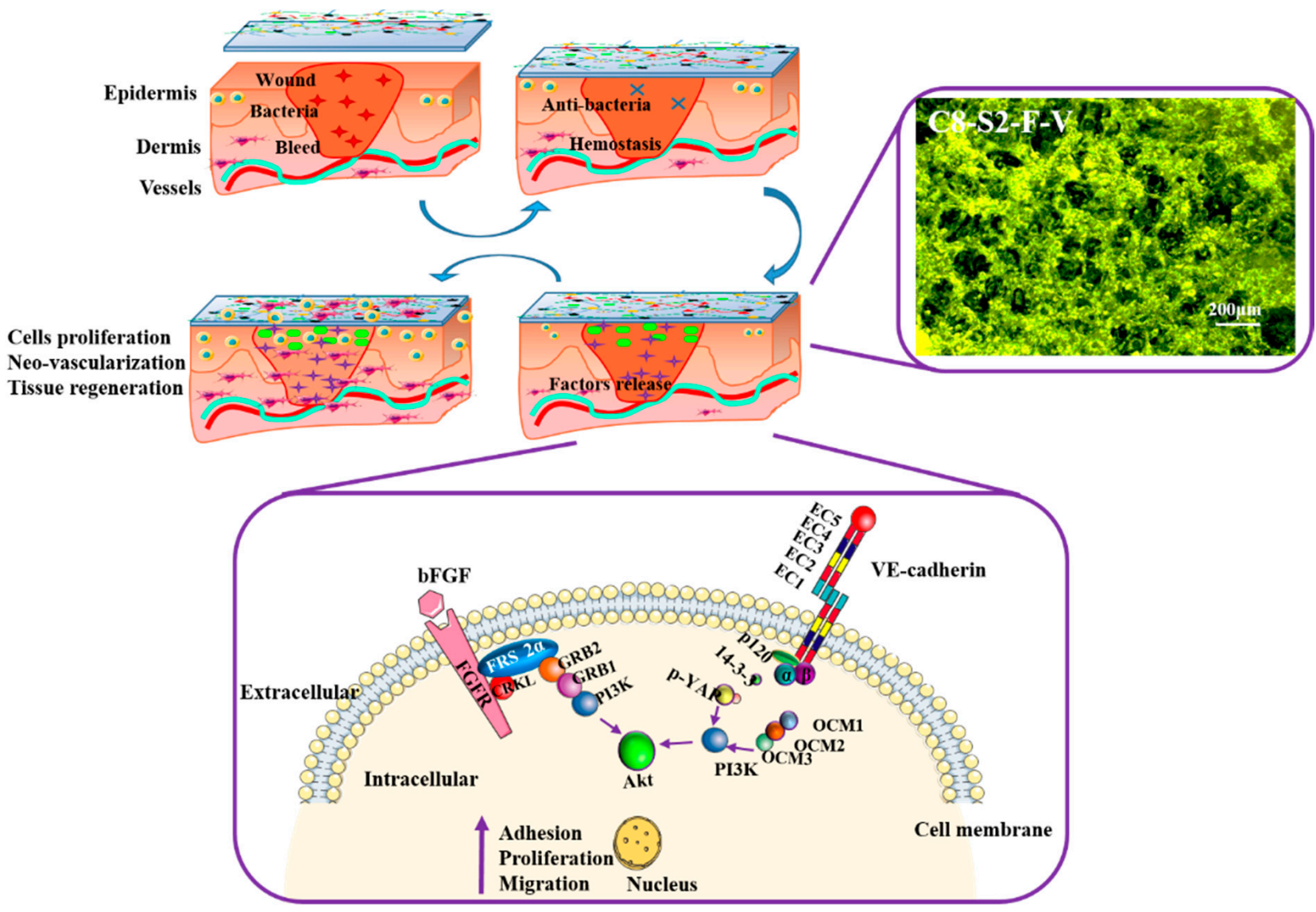

Figure 8. The relationship between hydrogels and wound healing process, involved in a cellular fluorescence image of the C8-S2-F-V hydrogel and the signaling pathways of FGF and VE-cadherin; CCM1, cerebral cavernous malformation protein 1; PI3K, phosphatidylinositol 3 kinases; YAP, yesassociated protein; FGFR, FGF receptors. The scale bar stands for $200 \mu \mathrm{m}$ in Figure 8.

Besides the adhesion of cells, angiogenesis also plays an essential role in skin wound healing [46]. There was evidence that proved that in VE-cadherin-deficient embryos, there was no sign of angiogenic sprouting. Furthermore, VE-cadherin activities have been proved to participate in the process of blood vessel proliferation and migration [47].

\section{Experimental and Methods}

\subsection{Materials and Reagents}

Chitosan (CS, deacetylation degree of $\geq 95 \%$, a viscosity of $100-200 \mathrm{mPa}$.s at $20^{\circ} \mathrm{C}$ ) was from Aladdin Co. (Shanghai, China). Alginate (SA) was from Macklin Co. (Beijing, China). Vascular endothelial cadherin (VE-cadherin) was purchased from Boster Co. (Wuhan, China). 1-3-Dimethylaminopropyl)-3-ethylarbidiimide Hydrochloride $\left(\mathrm{C}_{8} \mathrm{H}_{17} \mathrm{~N}_{3} \cdot \mathrm{HCl},>98.0 \%\right)$ were from TCI Co. (Shanghai, China). N-Hydroxysuccinimide ( $\geq 97.0 \%)$, Poly(ethylene glycol) diacrylate(PEGDA, Mn $\approx 700 \mathrm{Da})$ and Rhodamine 123 were obtained from Sigma-Aldrich. 
The cells' culture mediums, DMEM-High Glucose, came from BD Biosciences. Servicebio Technology CO., LTD (Wuhan, China) offered hematoxylin-eosin dye. All the other reagents were the highest analytical purity $(>99.9 \%)$.

\subsection{Preparation of Complex Hydrogels (CS/SA/PEGDDA Gel)}

Briefly, $0.2 \mathrm{~g}$ CS was dissolved in $10 \mathrm{~mL} 0.1 \mathrm{M}$ glacial acetic acid, $1 \mathrm{~g}$ PEGDA was dissolved in $10 \mathrm{~mL} 0.01 \mathrm{M}$ phosphate buffered saline (PBS), and $0.2 \mathrm{~g} \mathrm{SA}$ was dissolved in $10 \mathrm{~mL} 0.05 \mathrm{M}$ sodium bicarbonate $\left(\mathrm{NaHCO}_{3}\right)$. Subsequently, PEGDA was added to CS and formed a mixing solution. Then, the mixing solution was added to SA with the catalyzed EDC/NHS.

\subsection{Swelling Ratio and Degradation Ratio}

Swelling tests were used to determine the swelling ratio (SR) of the complex hydrogels, which were analyzed by the weight ratio of dried state (Wd) and fully swollen state (Ws). Firstly, the complex hydrogels were immersed in $0.01 \mathrm{M} \mathrm{PBS}$ at $37^{\circ} \mathrm{C}$ until the weight of all hydrogels was kept constant. Then the hydrogels were taken out, the superficial water of gels were removed by filter paper, and the weight of the gels was signed as Ws. After that, the gels were dried to a constant weight at $60^{\circ} \mathrm{C}$, and the weight was denoted as Wd. SR was calculated using the following formula: $\mathrm{SR}=(\mathrm{Ws}-\mathrm{Wd}) / \mathrm{Wd}$. The test was repeated three times at least.

Degradation tests were used to determine the degradation ratio (DR) of the complex hydrogels. Firstly, the complex hydrogels were immersed in $0.01 \mathrm{M}$ PBS at $37^{\circ} \mathrm{C}$ with shaking at $70 \mathrm{rpm}$ until the weight of all hydrogels was kept constant and the weight were denoted as $W_{0}$. At the predetermined time, the hydrogels were taken out, rinsed using RO water to remove excess salinity, the superficial water of gels were removed by filter paper, and the weight was denoted as $W^{\prime}$. DR of hydrogels was analyzed by the following formula: $\mathrm{DR}=\left(\mathrm{W}_{0}-\mathrm{W}^{\prime}\right) / \mathrm{W}_{0} \times 100 \%$. The test was repeated more than three times.

\subsection{Rheological Properties}

Hydrogel samples were prepared into parallel plates $(\sim 1 \mathrm{~mm}$ high $\times 25 \mathrm{~mm}$ in diameter) for compression test at $25^{\circ} \mathrm{C}$. The Storage Modulus $\left(\mathrm{G}^{\prime}\right)$ and Loss Modulus $\left(\mathrm{G}^{\prime \prime}\right)$ were carried out using a rheometer (Model DHR-1, TA Instruments) with an oscillation frequency ranging from 0.1 to $100 \mathrm{~Hz}$. All these tests were repeated at least three times.

\subsection{Scanning Electron Microscope (SEM)}

The internal morphology of the complex hydrogels was observed by a scanning electron microscope (SEM). Firstly, the prepared gel was fixed using $2.5 \%$ glutaraldehyde for $30 \mathrm{~min}$ at $25^{\circ} \mathrm{C}$. Secondly, the hydrogels were put into the liquid nitrogen for $-196^{\circ} \mathrm{C}$ overnight. Then, the frozen hydrogel was dried using a lyophilizer until all the water within the gels were removed. After that, the gel was cut, and the cross section was fixed on the clean conductive substrate using liquid silver paint to increase the conductivity, and the internal morphology was imaged by SEM (Philips Quanta 2000).

\subsection{Hemolysis and Whole Blood Dynamic Coagulation Evaluation}

The hemolysis test is a necessary experiment for blood compatibility evaluation, which could identify whether the red blood cells are ruptured or not after the hydrogel is connected to the blood. Firstly, the fresh rabbit blood with anticoagulation was centrifuged at $3000 \mathrm{rpm}$ for $15 \mathrm{~min}$ to acquire the lower blood cells, and then the blood cells were diluted to $2 \%$ using normal saline. The fresh rabbit blood diluted with $\mathrm{RO}$ was set as a positive control, and the fresh rabbit blood diluted with normal saline was set as a negative control. Secondly, $1 \mathrm{~mL}$ diluted blood cells were added to each hydrogel wells and cultured in an incubator shaker at $37^{\circ} \mathrm{C}$ for $1 \mathrm{~h}$. Then the immersion solution was aspirated and centrifuged at $3000 \mathrm{rpm}$ for $5 \mathrm{~min}$ to isolate the ruptured blood cells, and the supernate was suctioned to measure the absorbance at $540 \mathrm{~nm}$. The absorbance of hydrogels was signed 
as A, the absorbance of positive control was signed as B, and the absorbance of negative control was signed as $\mathrm{C}$. The hemolysis test of hydrogels was analyzed by the following formula: $(\mathrm{A}-\mathrm{C}) /(\mathrm{B}-\mathrm{C}) \times 100 \%$.

To evaluate the coagulation effect of the complex hydrogels, the whole blood dynamic coagulation assay in vitro was carried out. Firstly, $150 \mu \mathrm{L}$ fresh whole blood without anticoagulation was added onto the hydrogel surfaces and incubated at $37^{\circ} \mathrm{C}$ for 10,20 , 30, 40 and $50 \mathrm{~min}$, respectively. Secondly, each hydrogel wells were added to $\mathrm{RO}$ to dilute the red blood cells that un-involved coagulation. After $5 \mathrm{~min}$, the immersion solution was aspirated and measured the absorbance at $540 \mathrm{~nm}$, and the absorbance of hydrogels was signed as As. Then the hydrogels with sludged blood at different points in time were taken out and photographed. At the same time, $150 \mu \mathrm{L}$ fresh whole blood with anticoagulation was diluted with $\mathrm{RO}$, measured the absorbance at $540 \mathrm{~nm}$ and signed as $\mathrm{Aw}$, which involved the whole red blood cells. Therefore, the blood coagulant index (BCI) of hydrogels were analyzed by the following formula: As $/ \mathrm{Aw} \times 100 \%$.

\subsection{In Vitro and In Vivo Antibacterial Activities}

The antibacterial activities of complex hydrogels against Gram-negative bacteria E. coli and Gram-positive bacteria S. aureus in vitro were evaluated by hydrogel surface antibacterial assay. Firstly, a single colony was seeded in an aseptic beef extract-peptone medium and cultured in an incubator shaker at $37^{\circ} \mathrm{C}$ under the speed of $120 \mathrm{rpm}$ for $12 \mathrm{~h}$. Then the bacterial suspension was diluted using sterilized PBS to different bacterial concentration $\left(10^{3}, 10^{4}, 10^{5}, 10^{6}, 10^{7}, 10^{8} \mathrm{CFU} / \mathrm{mL}\right)$. Furthermore, the complex gels were made in culture dishes and placed in UV light for $30 \mathrm{~min}$; LB agar gel plates without hydrogels were as control, and were marked as blank. After that, sterilized PBS was added to the gels to immerse and rinse the gels, and then $10 \mu \mathrm{L}$ of the bacterial suspension were evenly spaced with different bacterial concentrations on the hydrogel surface and incubated at $37^{\circ} \mathrm{C}$ for $12 \mathrm{~h}$. Then the hydrogel plates and agar gel plates were taken photos to observe the colony-forming units (CFUs) on each plate. Then, to detect the CFUs on each plate, $1 \mathrm{~mL}$ sterilized PBS was added to each hydrogel plate to dissolve survived bacteria. After that, $10 \mu \mathrm{L}$ suspension above were added to the surface of agar gel and incubated at $37^{\circ} \mathrm{C}$ for $24 \mathrm{~h}$, and $10 \mu \mathrm{L}$ bacteria as control. After incubation, the number of CFUs on the LB agar gel plates were counted. The killing efficiency was calculated using the following formula: $\left(\mathrm{N}_{1}-\mathrm{N}_{2}\right) / \mathrm{N}_{1} \times 100 \%$, where $\mathrm{N}_{1}$ refers to the number of CFUs of control, and $\mathrm{N}_{2}$ refers to the number of CFUs of the survive to count on complex hydrogels. The antibacterial assay was repeated at least three times.

In this work, all of the experiments with animals were performed with the approval of the Local Ethical Committee of Southwest Jiaotong University and Laboratory Animal Administration Rules of China. All the animals were purchased from Dashuo Experiment Animals CO., LTD (Chengdu, China). Their experimental animal production license was authorized by Sichuan Animal Management Committee, the project identification approval code was "SCXK (chuan) 2020-030", and date was 6 March 2020. The antibacterial activities of complex hydrogels against Gram-negative bacteria E. coli and Gram-positive bacteria $S$. aureus in vivo were evaluated by an antibacterial assay using rats' full-thickness infected skin defect model. These experiments were carried out using Sprague-Dawley male rats, 3-4 weeks old, weight about $200 \mathrm{~g}$. Firstly, all rats back were shaved and $1.0 \mathrm{~cm}$ in diameter wounds were created. Secondly, $1 \mathrm{~mL}$ E. coli and S. aureus of the bacterial suspension $\left(10^{8} \mathrm{CFU} / \mathrm{mL}\right)$ were evenly spaced on the rats' wounds and maintained for $30 \mathrm{~min}$, respectively. Then the complex hydrogels were added to the infected wounds directly. After the wounds healing for $24 \mathrm{~h}$, those tissues were harvested and fixed using $4 \%$ paraformaldehyde overnight. Furthermore, embedding, paraffin section and gram staining to perform histological analysis. 


\subsection{In Vitro Compatibility Evaluation of Epithelial Cells}

In order to study the repair effect of complex hydrogel on epithelial tissue, the compatibility of the hydrogels with L929 and EC were evaluated. The EC (EC304) and the L929 were purchased from West Chain Hospital (Chengdu, Sichuan). They were cultured using the medium (DMEM High Glucose) containing 10\% fetal bovine serum (FBS) [48].

Before cell experiments, the complex gels were made in 12 pore plates and placed in UV light for $30 \mathrm{~min}$ to form a sterile environment. Every type of cells (L929, EC) $\left(3 \times 10^{4}\right.$ cells $\left./ \mathrm{mL}\right)$ were seeded onto the gels' surface and incubated at $37^{\circ} \mathrm{C}$ with $5 \% \mathrm{CO}_{2}$ for 1,3,7 and 12 days. Besides single cells culture, two type of cells (L929\&EC) were also seeded onto the gels. After seeding one type of cell onto the gels for $3 \mathrm{~h}$, another type of cell was seeded. After that, at the pointing time, $630 \mu \mathrm{L}$ cell medium and $70 \mu \mathrm{L}$ cell counting kit-8(CCK-8) were added to each sample to investigate the whole sample's cell number, which includes the surface and the interior cells of the hydrogel. Then, the samples were fixed using $2.5 \%$ glutaraldehyde overnight and stained by Rhodamine 123 and DAPI to observe the distribution of cells in the hydrogels using a fluorescence microscope and confocal microscopy (NIKON, A1 + N-ATORM).

\subsection{In Vivo Wound Healing and Histological Analysis}

The wound healing ability of complex hydrogels was evaluated using a full-thickness skin wound model. All the animals were purchased from Dashuo Experiment Animals CO., LTD (Chengdu, China). Their experimental animal production license was authorized by Sichuan Animal Management Committee, the project identification approval code was "SCXK (chuan) 2020-030", and date was 6 March 2020. Male Sprague-Dawley rats (100-120 g) were anaesthetized, dorsum was shaved, and four round full-thickness wounds $(1.0 \mathrm{~cm}$ in diameter) were created. Then the wounds were covered with the complex hydrogel disks, and the sterilized PBS were set as control. A gauze was used to cover the wound dress. Ultimately, after wound healing for 3, 7 and 14 days, the skin tissues were excised and fixed using $4 \%$ paraformaldehyde overnight. Furthermore, embedding, paraffin section and hematoxylin and eosin (H\&E) staining to perform histological analysis.

\subsection{Statistical Methods}

At least three parallel samples were prepared in each experiment. The statistical analysis used Origin 9.0, and data were expressed as mean \pm standard deviation (SD). And one-way ANOVA tests were employed to show statistical differences between groups, $* p<0.05$ was considered statistically significant.

\section{Conclusions}

A series of hemostatic, antibacterial and super cytocompatibility complex hydrogels based on PEGDA, CS and SA, were successfully prepared through the crosslinking of the carboxyl of alginate and the amino and the hydroxy of chitosan. These complex hydrogels exhibited multifunction like suitable swelling, tunable pore size and rheological property and controlled degradation behaviors. Besides, the presents of chitosan endowed hydrogels with excellent hemostatic and antibacterial ability, which solved the problem of hemostasis and inflammation at the wound healing first two stages. Besides, the basic hydrogels could promote the adhesion and proliferation of L929 and EC to a certain degree. Additionally, the C8-S2 hydrogel with FGF and VE-cadherin exhibited unexceptionable cytocompatibility to the co-culture of L929 and EC, especially in the proliferation of the two cells after culturing for 7 and 12 days. The hydrogels could provide a 3D cell culture niche to enhance cell-cell and cell-ECM links, and the introduction of FGF and VE-cadherin could promote the proliferation and migration of cells through the PI3K/AKT pathway signaling pathways. Furthermore, the histological evaluation showed a better wound healing effect in a full-thickness skin defected model. These properties make the complex hydrogels more competitive in the promising application of a full-thickness skin wound healing process. 
Author Contributions: L.W., Methodology, Formal Analysis, Investigation, Writing-Original Draft; J.T., Formal Analysis, Data Curation; L.L., Investigation, Formal Analysis; S.L., Data Curation, Formal Analysis; H.W., Validation, Software; J.C., Resources, Project Administration, Conceptualization, Supervision, Writing-Review and Editing; Y.W., Methodology, Conceptualization; T.L., WritingReview and Editing. All authors have read and agreed to the published version of the manuscript.

Funding: This research was funded by the National Natural Science Foundation of China (No.31870955\#) and the National Key Research and Development of China (2020YFC1107300-03) for financial support.

Institutional Review Board Statement: All the animals were purchased from Dashuo Experiment Animals CO., LTD (Chengdu, China). Their experimental animal production license was authorized by Sichuan Animal Management Committee, the project identification approval code was "SCXK (chuan) 2020-030", and date was 6 March 2020.

Informed Consent Statement: Not applicable.

Acknowledgments: We thank the National Natural Science Foundation of China (No.31870955\#) and the National Key Research and Development of China (2020YFC1107300-03) for financial support.

Conflicts of Interest: The authors declare no conflict of interest. The funders had no role in the design of the study; in the collection, analyses, or interpretation of data; in the writing of the manuscript, or in the decision to publish the results.

\section{References}

1. Du, X.; Liu, Y.; Wang, X.; Yan, H.; Wang, L.; Qu, L.; Kong, D.; Qiao, M.; Wang, L. Injectable hydrogel composed of hydrophobically modified chitosan/oxidized-dextran for wound healing. Mater. Sci. Eng. C Mater. Biol. Appl. 2019, 104, 109930. [CrossRef]

2. Rousselle, P.; Montmasson, M.; Garnier, C. Extracellular matrix contribution to skin wound re-epithelialization. Matrix Biol. 2019, 75-76, 12-26. [CrossRef]

3. Liang, Y.; Zhao, X.; Hu, T.; Chen, B.; Yin, Z.; Ma, P.X.; Guo, B. Adhesive Hemostatic Conducting Injectable Composite Hydrogels with Sustained Drug Release and Photothermal Antibacterial Activity to Promote Full-Thickness Skin Regeneration During Wound Healing. Small 2019, 15, e1900046. [CrossRef]

4. Liang, Y.; He, J.; Guo, B. Functional Hydrogels as Wound Dressing to Enhance Wound Healing. ACS Nano 2021, 15, 12687-12722. [CrossRef]

5. Zare-Gachi, M.; Daemi, H.; Mohammadi, J.; Baei, P.; Bazgir, F.; Hosseini-Salekdeh, S.; Baharvand, H. Improving anti-hemolytic, antibacterial and wound healing properties of alginate fibrous wound dressings by exchanging counter-cation for infected full-thickness skin wounds. Mater. Sci. Eng. C Mater. Biol. Appl. 2020, 107, 110321. [CrossRef]

6. Bakhsheshi-Rad, H.R.; Hadisi, Z.; Ismail, A.F.; Aziz, M.; Akbari, M.; Berto, F.; Chen, X.B. In vitro and in vivo evaluation of chitosan-alginate/gentamicin wound dressing nanofibrous with high antibacterial performance. Polym. Test. 2020, 82, 106298. [CrossRef]

7. Guerle-Cavero, R.; Lleal-Fontas, B.; Balfagon-Costa, A. Creation of Ionically Crosslinked Tri-Layered Chitosan Membranes to Simulate Different Human Skin Properties. Materials 2021, 14, 1807. [CrossRef]

8. Chen, K.; Wang, F.; Liu, S.; Wu, X.; Xu, L.; Zhang, D. In situ reduction of silver nanoparticles by sodium alginate to obtain silver-loaded composite wound dressing with enhanced mechanical and antimicrobial property. Int. J. Biol. Macromol. 2020, 148, 501-509. [CrossRef]

9. Gao, Y.; Wang, Y.R.; Xia, S.; Gao, G.H. An environment-stable hydrogel with skin-matchable performance for human-machine interface. Sci. China Mater. 2021, 64, 2313-2324. [CrossRef]

10. Yazdi, M.K.; Vatanpour, V.; Taghizadeh, A.; Taghizadeh, M.; Ganjali, M.R.; Munir, M.T.; Habibzadeh, S.; Saeb, M.R.; Ghaedi, M. Hydrogel membranes: A review. Mater. Sci. Eng. C Mater. Biol. Appl. 2020, 114, 111023. [CrossRef]

11. Cascone, S.; Lamberti, G. Hydrogel-based commercial products for biomedical applications: A review. Int. J. Pharm. 2020, 573, 118803. [CrossRef] [PubMed]

12. Mohamad, N.; Loh, E.Y.X.; Fauzi, M.B.; Ng, M.H.; Mohd Amin, M.C.I. In vivo evaluation of bacterial cellulose/acrylic acid wound dressing hydrogel containing keratinocytes and fibroblasts for burn wounds. Drug Deliv. Transl. Res. 2019, 9, 444-452. [CrossRef] [PubMed]

13. Liang, Y.; Chen, B.; Li, M.; He, J.; Yin, Z.; Guo, B. Injectable Antimicrobial Conductive Hydrogels for Wound Disinfection and Infectious Wound Healing. Biomacromolecules 2020, 21, 1841-1852. [CrossRef] [PubMed]

14. Yu, Y.; Yuk, H.; Parada, G.A.; Wu, Y.; Liu, X.; Nabzdyk, C.S.; Youcef-Toumi, K.; Zang, J.; Zhao, X. Multifunctional “Hydrogel Skins" on Diverse Polymers with Arbitrary Shapes. Adv. Mater. 2019, 31, e1807101. [CrossRef]

15. Qianqian, O.; Songzhi, K.; Yongmei, H.; Xianghong, J.; Sidong, L.; Puwang, L.; Hui, L. Preparation of nano-hydroxyapatite/chitosan /tilapia skin peptides hydrogels and its burn wound treatment. Int. J. Biol. Macromol. 2021, 181, 369-377. [CrossRef]

16. Furlani, F.; Rossi, A.; Grimaudo, M.A.; Bassi, G.; Giusto, E.; Molinari, F.; Lista, F.; Montesi, M.; Panseri, S. Controlled Liposome Delivery from Chitosan-Based Thermosensitive Hydrogel for Regenerative Medicine. Int. J. Mol. Sci. 2022, 23, 894. [CrossRef] 
17. Thakur, V.K.; Thakur, M.K. Recent advances in graft copolymerization and applications of chitosan: A review. ACS Sustain. Chem. Eng. 2014, 2, 2637-2652. [CrossRef]

18. Thakur, S.; Sharma, B.; Verma, A.; Chaudhary, J.; Tamulevicius, S.; Thakur, V.K. Recent progress in sodium alginate based sustainable hydrogels for environmental applications. J. Clean. Prod. 2018, 198, 143-159. [CrossRef]

19. Verma, A.; Thakur, S.; Mamba, G.; Gupta, R.K.; Thakur, P.; Thakur, V.K. Graphite modified sodium alginate hydrogel composite for efficient removal of malachite green dye. Int. J. Biol. Macromol. 2020, 148, 1130-1139. [CrossRef]

20. Poonguzhali, R.; Khaleel Basha, S.; Sugantha Kumari, V. Novel asymmetric chitosan/PVP/nanocellulose wound dressing: In vitro and in vivo evaluation. Int. J. Biol. Macromol. 2018, 112, 1300-1309. [CrossRef]

21. Deng, P.; Jin, W.; Liu, Z.; Gao, M.; Zhou, J. Novel multifunctional adenine-modified chitosan dressings for promoting wound healing. Carbohydr. Polym. 2021, 260, 117767. [CrossRef] [PubMed]

22. Masood, N.; Ahmed, R.; Tariq, M.; Ahmed, Z.; Masoud, M.S.; Ali, I.; Asghar, R.; Andleeb, A.; Hasan, A. Silver nanoparticle impregnated chitosan-PEG hydrogel enhances wound healing in diabetes induced rabbits. Int. J. Pharm. 2019, 559, 23-36. [CrossRef] [PubMed]

23. Xue, H.; Hu, L.; Xiong, Y.; Zhu, X.; Wei, C.; Cao, F.; Zhou, W.; Sun, Y.; Endo, Y.; Liu, M.; et al. Quaternized chitosan-Matrigelpolyacrylamide hydrogels as wound dressing for wound repair and regeneration. Carbohydr. Polym. 2019, 226, 115302. [CrossRef] [PubMed]

24. Miguel, S.P.; Moreira, A.F.; Correia, I.J. Chitosan based-asymmetric membranes for wound healing: A review. Int. J. Biol. Macromol. 2019, 127, 460-475. [CrossRef] [PubMed]

25. Baysal, K.; Aroguz, A.Z.; Adiguzel, Z.; Baysal, B.M. Chitosan/alginate crosslinked hydrogels: Preparation, characterization and application for cell growth purposes. Int. J. Biol. Macromol. 2013, 59, 342-348. [CrossRef] [PubMed]

26. Zhang, M.; Zhao, X. Alginate hydrogel dressings for advanced wound management. Int. J. Biol. Macromol. 2020, 162, 1414-1428. [CrossRef]

27. Ehterami, A.; Salehi, M.; Farzamfar, S.; Samadian, H.; Vaez, A.; Ghorbani, S.; Ai, J.; Sahrapeyma, H. Chitosan/alginate hydrogels containing Alpha-tocopherol for wound healing in rat model. J. Drug Deliv. Sci. Technol. 2019, 51, 204-213. [CrossRef]

28. Lehnert, S.; Sikorski, P. Tailoring the assembly of collagen fibers in alginate microspheres. Mater. Sci. Eng. C Mater. Biol. Appl 2021, 121, 111840. [CrossRef]

29. Yao, Y.; Zhang, A.; Yuan, C.; Chen, X.; Liu, Y. Recent trends on burn wound care: Hydrogel dressings and scaffolds. Biomater. Sci. 2021, 9, 4523-4540. [CrossRef]

30. Prudovsky, I. Cellular Mechanisms of FGF-Stimulated Tissue Repair. Cells 2021, 10, 1830. [CrossRef] [PubMed]

31. Firoozi, N.; Kang, Y. Immobilization of FGF on Poly(xylitol dodecanedioic Acid) Polymer for Tissue Regeneration. Sci. Rep. 2020, 10, 10419. [CrossRef]

32. Karimi, M.; Maghsoud, Z.; Halabian, R. Effect of Preconditioned Mesenchymal Stem Cells with Nisin Prebiotic on the Expression of Wound Healing Factors Such as TGF- $\beta 1$, FGF-2, IL-1, IL-6, and IL-10. Regen. Eng. Transl. Med. 2021, 7, 30-40. [CrossRef]

33. Xie, Y.; Su, N.; Yang, J.; Tan, Q.; Huang, S.; Jin, M.; Ni, Z.; Zhang, B.; Zhang, D.; Luo, F.; et al. FGF/FGFR signaling in health and disease. Signal Transduct. Target. Ther. 2020, 5, 181. [CrossRef]

34. Mossahebi-Mohammadi, M.; Quan, M.; Zhang, J.S.; Li, X. FGF Signaling Pathway: A Key Regulator of Stem Cell Pluripotency. Front. Cell Dev. Biol. 2020, 8, 79. [CrossRef]

35. Jin, S.; Yang, C.; Huang, J.; Liu, L.; Zhang, Y.; Li, S.; Zhang, L.; Sun, Q.; Yang, P. Conditioned medium derived from FGF-2modified GMSCs enhances migration and angiogenesis of human umbilical vein endothelial cells. Stem Cell Res. Ther. 2020, 11, 68. [CrossRef]

36. Sasaki, J.I.; Zhang, Z.; Oh, M.; Pobocik, A.M.; Imazato, S.; Shi, S.; Nor, J.E. VE-Cadherin and Anastomosis of Blood Vessels Formed by Dental Stem Cells. J. Dent. Res. 2020, 99, 437-445. [CrossRef]

37. Duong, C.N.; Vestweber, D. Mechanisms Ensuring Endothelial Junction Integrity Beyond VE-Cadherin. Front. Physiol. 2020, 11, 519. [CrossRef]

38. Gao, C.; Zhang, Y.; Xie, J.H.; Wang, X.P.; Cao, L.; Chen, G.Q.; Mao, H.L.; Bi, X.D.; Gu, Z.W.; Yang, J. VE-cadherin functionalized injectable PAMAM/HA hydrogel promotes endothelial differentiation of hMSCs and vascularization. Appl. Mater. Today 2020, 20, 100690. [CrossRef]

39. Huang, L.X.; Abdalla, A.M.E.; Xiao, L.; Yang, G. Biopolymer-Based Microcarriers for Three-Dimensional Cell Culture and Engineered Tissue Formation. Int. J. Mol. Sci. 2020, 21, 1895. [CrossRef]

40. Chou, T.C.; Fu, E.; Wu, C.J.; Yeh, J.H. Chitosan enhances platelet adhesion and aggregation. Biochem. Biophys. Res. Commun. 2003, 302, 480-483. [CrossRef]

41. Zhong, Y.; Hu, H.; Min, N.; Wei, Y.; Li, X.; Li, X. Application and outlook of topical hemostatic materials: A narrative review. Ann. Transl. Med. 2021, 9, 577. [CrossRef]

42. Rondon, E.P.; Benabdoun, H.A.; Vallières, F.; Petrônio, M.S.; Tiera, M.J.; Benderdour, M.; Fernandes, J.C. Evidence Supporting the Safety of Pegylated Diethylaminoethyl-Chitosan Polymer as a Nanovector for Gene Therapy Applications. Int. J. Nanomed. 2020, 15, 6183-6200. [CrossRef]

43. Chen, K.Y.; Chen, Y.C.; Lin, T.H.; Yang, C.Y.; Kuo, Y.W.; Lei, U. Hemostatic Enhancement via Chitosan Is Independent of Classical Clotting Pathways-A Quantitative Study. Polymers 2020, 12, 2391. [CrossRef] 
44. Li, J.H.; Zhuang, S.L. Antibacterial activity of chitosan and its derivatives and their interaction mechanism with bacteria: Current state and perspectives. Eur. Polym. J. 2020, 138, 109984. [CrossRef]

45. Lampugnani, M.G.; Dejana, E.; Giampietro, C. Vascular Endothelial (VE)-Cadherin, Endothelial Adherens Junctions, and Vascular Disease. Cold Spring Harb. Perspect. Biol. 2018, 10, a029322. [CrossRef]

46. Sorg, H.; Tilkorn, D.J.; Hager, S.; Hauser, J.; Mirastschijski, U. Skin Wound Healing: An Update on the Current Knowledge and Concepts. Eur. Surg. 2017, 58, 81-94. [CrossRef]

47. Malinova, T.S.; Angulo-Urarte, A.; Nuchel, J.; Tauber, M.; van der Stoel, M.M.; Janssen, V.; de Haan, A.; Groenen, A.G.; Tebbens, M.; Graupera, M.; et al. A junctional PACSIN2/EHD4/MICAL-L1 complex coordinates VE-cadherin trafficking for endothelial migration and angiogenesis. Nat. Commun. 2021, 12, 2610. [CrossRef]

48. Tan, J.Y.; Li, L.; Wang, H.R.; Wei, L.; Gao, X.L.; Zeng, Z.; Liu, S.N.; Fan, Y.H.; Liu, T.; Chen, J.Y. Biofunctionalized fibrin gel co-embedded with BMSCs and VEGF for accelerating skin injury repair. Mater. Sci. Eng. C Mater. 2021, 121, 111749. [CrossRef] 